Billing, B. H., Williams, R., and Richards, T. G. (1964). Clinical Science, 27,245 .

Black, M., and Billing, B. H. (1969). New England fournal of Medicine, 280, 1266 .

Black, M., and Billing, B. H. (1970). Lancet, 1, 1359.

Black, M., Billing, B. H., and Heirwegh, K. P. M. (1970). Clinica Chimica Acta, 29, 27.

Bloomer, J. R., Barrett, P. V., Rodkey, F. L., and Berlin, N. I. (1971) Gastroenterology, 61, 479.

Cherrick, G. R., Stein, S. W., and Leevy, C. M. (1960). Journal of Clinical Investigation, 39, 592 .

Felscher, B. F., Rickard, D., and Redeker, A. G. (1970). New England Fournal of Medicine, 283, 170.

Fleischner, G., Robbins, J., and Arias, I. M. (1972). fournal of Clinical Investigation, 51, 677 .

Foulk, W. T., Butt, H. R., Owen, C. A., jun., and Whitcomb, F. F. (1959). Medicine, 38, 25.
Gilbert, A., and Lereboullet, P. (1901). Semaine Médicale, 21, 241.

Gilbert, A., and Herscher, M. (1906). Press Médicale, 14, 209.

Laurell, C.-B., and Nyman, N. (1957). Blood, 12, 493.

Levi, A. J., Gatmaitan, Z., and Arias, I. M. (1969). Fournal of Clinical Investigation, 48, 2156.

Lowy, O. H., Rosebrough, N. J., Farr, A. L., and Randall, A. J. (1951). fournal of Biological Chemistry, 193, 265.

Mancini, G., Carbonara, O., and Heremans, J. F. (1965). Immunochemistry, $2,235$.

Michaelsson, M., Nosslin, B., and Sjölin, S. (1965). Pediatrics, 35, 925.

Murphy, B. E. P. (1967). Fournal of Clinical Endocrinology and Metabolism

Ockner, R. K., Manning, J. A., Poppenhausen, R. B., and Ho, W. K. L. (1972). Science, 177, 56

Reemstsma, K., Hattinger, G. C., and De Graff, A. C. (1960). Surgery, Gynecology and Obstetrics, 110, 353.

\title{
Possible Role of Hormones in Treatment of Metastatic Testicular Teratomas: Tumour Regression with Medroxyprogesterone Acetate
}

\author{
H. J. G. BLOOM, W. F. HENDRY
}

British Medical fournal, 1973, 3, 563-567

\section{Summary}

Three patients in a consecutive series of 16 cases of metastatic malignant teratoma testis have shown wellmarked tumour regression during hormone treatment. In two cases multiple lung metastases had previously failed to respond to actinomycin $D$ therapy, and following treatment with medroxyprogesterone acetate one patient had well-marked selective tumour regression for nine month s while the other is alive, well, and free from disease at seven years. The third case was treated with a combination of actinomycin $D$ and medroxyprogesterone acetate and is alive and disease-free at two years.

Attention is drawn to this preliminary study in the hope of stimulating interest in the possible value of hormones, either alone or combined with chemotherapy and irradiation, in the treatment of metastatic testicular teratoma. Multicentre prospective clinical trials are now needed if knowledge is to be advanced in this field.

\section{Introduction}

Early death is to be expected for most patients with teratoma of the testis once blood-borne metastases appear. In recent years, chemotherapy has brought some hope of prolonging useful life in a few of these cases (Hill et al., 1972; Smithers, 1972). At the present time, however, it seems.likely that longterm control or cure can be achieved in no more than about $10 \%$ of cases of metastatic teratoma using cytotoxic drugs, though perhaps some degree of regression, which is usually brief, can be seen in up to $50 \%$ of such cases (Mackenzie, 1966; Kennedy, 1970; Foley et al., 1972).

Radiotherapy may achieve regression of extensive pulmonary metastases from testicular teratoma with temporary relief of

Royal Marsden Hospital and Institute of Cancer Research, London SW3 6JJ and St. Peter's Group of Hospitals and Institute of Urology, London WC2

H. J. G. BLOOM, M.D., F.F.R., Consultant Radiotherapist

W. F. HENDRY, CH.M., F.R.C.S., Senior Lecturer in Urology distressing symptoms (Cox et al., 1972). This treatment may be of greater value than chemotherapy in cases with limited lung deposits (Werf-Messing, 1973).

The testis is a member of the endocrine system and a target organ for pituitary gonadotrophins. It was therefore only natural to consider whether hormonal changes may influence testicular tumours, as with other tumours arising in target organs such as the breast and prostate. During a series of animal experiments in which the effect of various hormones on dimethylnitrosamine-induced renal tumours in rats was being investigated in our laboratories, we observed severe testicular atrophy after prolonged administration of medroxyprogesterone acetate (MPA) (H. J. G. Bloom and J. Dalton, unpublished observations, 1965). Other workers have reported inhibition of spermatogenesis with atrophy of testicular tubular epithelium in experimental animals after administration of this agent (Ericsson and Dutt, 1965; Ronzoni et al., 1969). Depression of plasma testosterone by MPA has been reported in man (Rivarola et al., 1968). The inhibitory effect of MPA on the normal testis, and its known anti-tumour effect in patients with cancer of the endometrium, breast (Briggs et al., 1967), and kidney (Bloom, 1964, 1971; Samuels et al., 1968) suggested a trial of this hormone against metastatic testicular teratomas, particularly since chemotherapy had met with such limited success in this disease. MPA is a powerful synthetic progestational agent which can be given by mouth. Unlike cytotoxic agents it has minimal side effects, even in high doses, and often produces subjective improvement.

The main purpose of this paper is to report objective improvement in three of 16 patients with metastatic testicular teratoma treated with MPA, in two of whom actinomycin D had already failed to control the disease, and to try to revive interest in the possible value of a hormonal approach to the treatment of these highly lethal tumours once surgery and radiotherapy are no longer feasible.

\section{Case Reports}

CASE 1

The patient, aged 49, underwent right orchidectomy for a testicular tumour in October 1965. Histological examination showed a malignant teratoma "intermediate type B" of the British Testicular Tumour Panel and Registry (T.T.P.R.) classification, or "embryonal carcinoma" of the American Armed Forces Institute of Pathology 


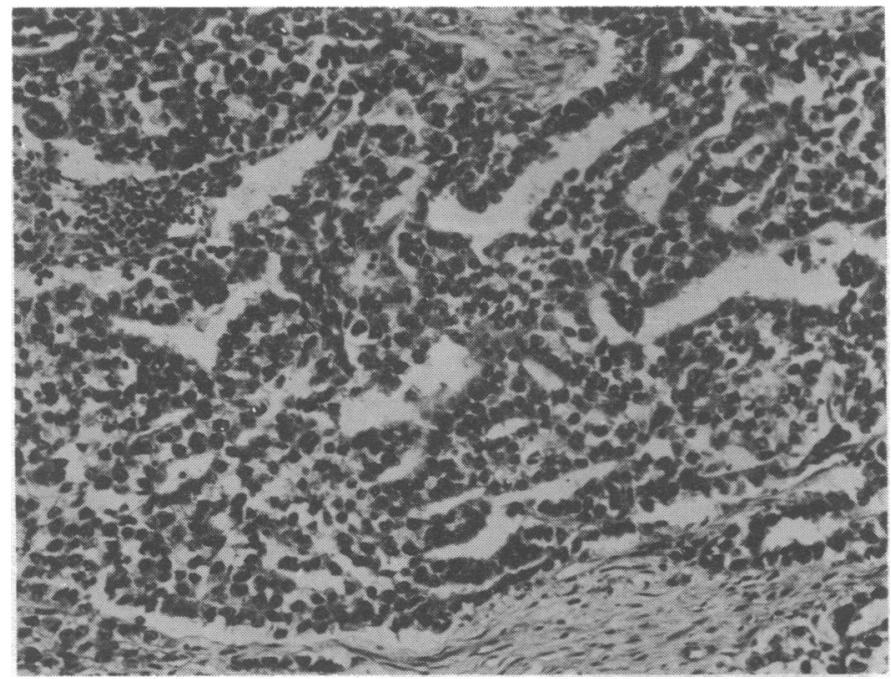

FIG. 1-Case 1. Malignant testicular teratoma (intermediate type B) composed largely of undifferentiated epithelium but showing some glandular orientation of the cells. $(\times 190$.)

(A.F.I.P.) nomenclature (fig. 1). Invasion of intratesticular lymphatics and of spermatic veins and lymphatics was present.

Chest $x$-ray examination at the time of operation showed a 2 -cm opacity in the left lower zone, confirmed by tomography. Lymphangiogram showed bilateral involvement of $\mathrm{L} 1$ and $\mathrm{L2}$ para-aortic nodes. Intravenous pyelogram showed lateral displacement of the upper right ureter. Urine gonadotrophins were 47 human menopausal gonadotrophin (HMG) units/24 hr (mouse uterine weight assay). The pelvic and para-aortic nodes were treated with $6 \mathrm{MeV} x$-rays, a tumour dose of 3,500 rads being given in 32 days. This treatment was combined with the administration of actinomycin D, $500 \mu \mathrm{g}, 30$ minutes before irradiation on each of five consecutive days. A further course of actinomycin D over four days was given one month later. A repeat chest $x$-ray film on 15 February 1966 showed multiple bilateral deposits which were increasing rapidly in size. Since the two courses of actinomycin D failed to control the pulmonary metastases, treatment was changed to MPA, $100 \mathrm{mg}$ three times daily by mouth, beginning 15 February 1966 (fig. 2). A chest $x$-ray picture on 12 April

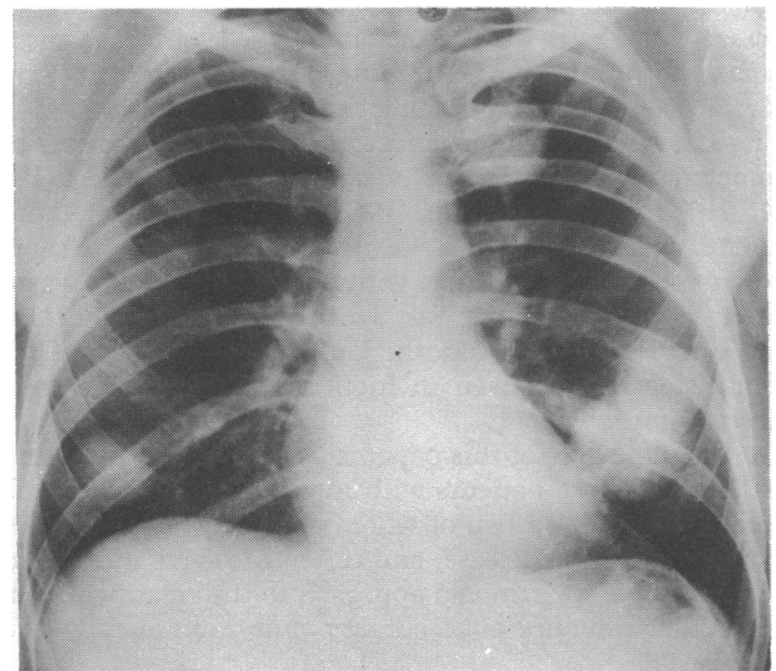

FIG. 2-Case 1. Advancing bilateral pulmonary metastases during treatment with actinomycin $\mathrm{D}$.

1966 showed that the metastases were much smaller, and by June they had completely disappeared (figs. 3 and 4). Urine gonadotrophins had fallen to 9 HMG units/24 hr. Treatment with MPA was continued for five years, decreasing the dose slowly by $50 \mathrm{mg}$ decrements, and finally stopping the hormone in June 1971 . A chest $x$-ray picture in January 1973 showed no sign of tumour recurrence, and the patient was alive and well seven years after beginning hormone treatment.

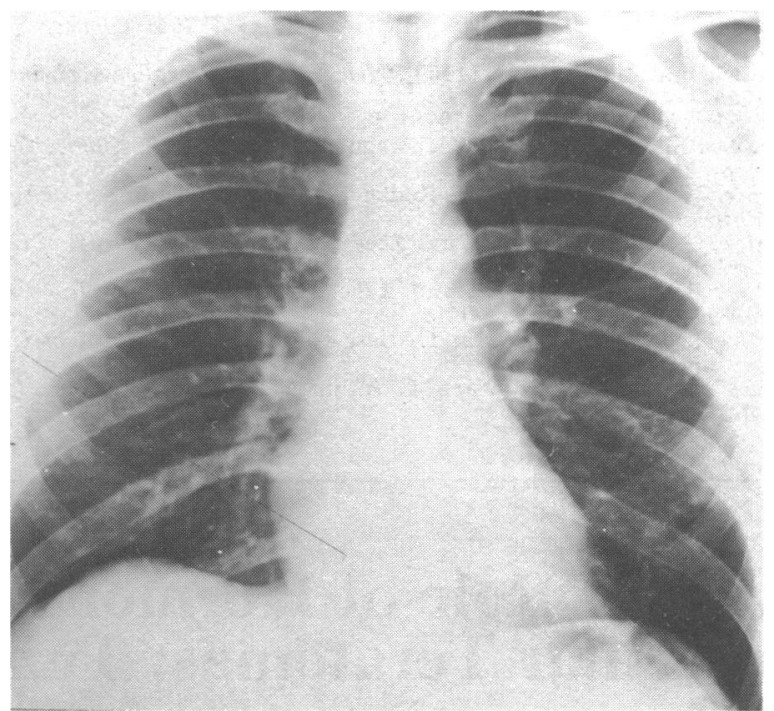

FIG. 3-Case 1. Disappearance of all lung metastases during treatment with medroxyprogesterone acetate. Follow-up chest $x$-ray picture seven years after starting hormone treatment.

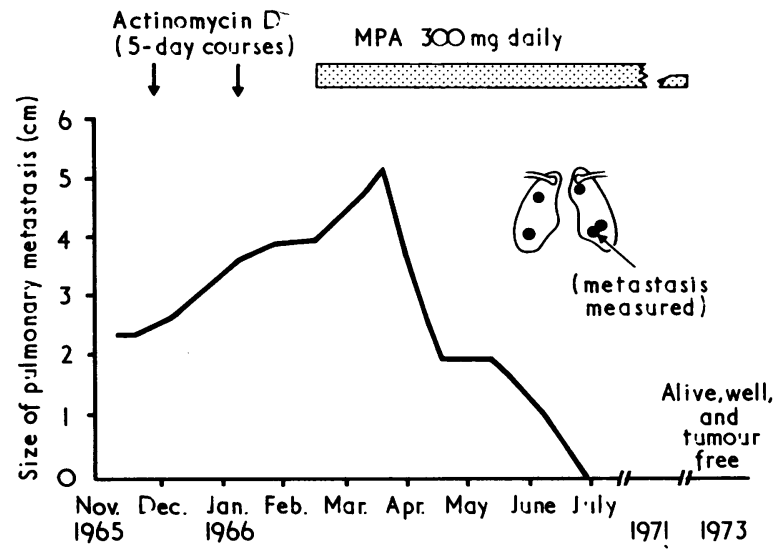

FIG. 4-Case 1. Tumour growth rate of largest metastasis at base of left lung (see fig. 2). Note continued growth during two courses of actinomycin D and rapid regression after changing to medroxyprogesterone (MPA). All deposits disappeared at a similar rate, the lungs becoming radiologically clear within four months.

CASE 2

This patient, aged 34, underwent right orchidectomy for a testicular tumour in December 1964. Histological examination showed differentiation to various types of epithelium, cartilage, and connective tissue. (Malignant teratoma intermediate type $A$ of the T.T.P.R. classification; teratocarcinoma of the A.F.I.P. nomenclature.)

A chest $x$-ray picture was clear. Lymphogram showed bilateral deposits in the L2-L4 para-aortic nodes. Intravenous pyelogram showed outward displacement of the left kidney by large metastatic lymph nodes. Urinary gonadotrophins were $94 \mathrm{HMG}$ units/24 hr.

The pelvic and para-aortic nodes were treated with supervoltage irradiation, a maximum tumour dose of 5,000 rads being delivered in 50 days using $6 \mathrm{MeV} x$-rays. On 3 March 1965 a 2-cm lymph node became palpable in the left supraclavicular fossa. Radiotherapy was now extended to include the mediastinum and supraclavicular regions, which ultimately received 4,500 rads in 45 days; an additional dose of 2,000 rads was then given to residual tumour in the left supraclavicular region.

Chest $x$-ray examination on 26 October 1965 showed bilateral pulmonary opacities. Treatment with actinomycin D was initiated in November 1965, when a test dose of $250 \mu \mathrm{g}$ was followed by two doses of $500 \mu \mathrm{g}$ on consecutive days. Further courses of actinomycin D were given in November and December 1965, each consisting of $500 \mu \mathrm{g}$ daily for five days. 
A chest $x$-ray picture on 11 January 1966 showed that the pulmonary opacities were larger and more numerous. Treatment with MPA, $100 \mathrm{mg}$ three times daily by mouth, was started on 19 January 1966, at which time the left supraclavicular node still measured 2-cm in diameter. A chest $x$-ray picture on 15 March showed that the opacities had continued to grow. The dose of MPA was therefore increased to $500 \mathrm{mg}$ daily. By 17 May the left supraclavicular node was smaller, and a chest $x$-ray picture on 14 June showed that many opacities had disappeared. Urinary gonadotrophins had fallen to 25 HMG units/24 hr. By 28 June the left supraclavicular node was no longer palpable. An $x$-ray picture on 13 September showed persistence of only one large opacity in the left base, and some collapse of the right lower lobe (fig. 5). Six months later, in March 1967, further opacities began to appear and enlarge. In June the patient developed a fever and a right pleural effusion. Bronchoscopy at this stage showed necrotic tumour obstructing the right main bronchus, a biopsy of which showed anaplastic malignant teratoma. His general condition deteriorated with hepatomegaly, and death occurred on 22 August 1967. Permission for necropsy was not given.

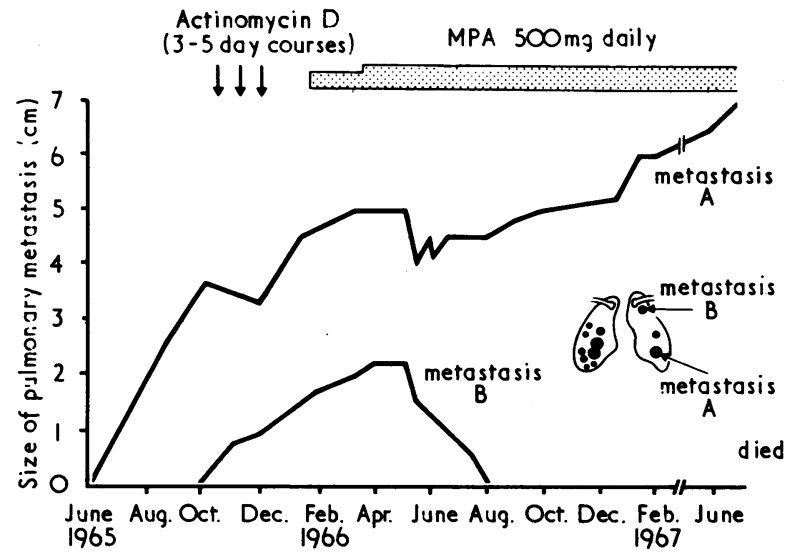

FIG. 5-Case 2. Tumour growth rate of two metastases in left lung. That for deposit $B$ in upper zone reflects general regression and disappearance of most metastases after dose of medroxyprogesterone (MPA) was increased to $500 \mathrm{mg}$ daily. Growth rate of deposit $\mathrm{A}$ at base was temporarily reduced with actinomycin $\mathrm{D}$ and subsequently with increased dose of progesterone

\section{CASE 3}

A 28-year-old man underwent left orchidectomy in January 1971. Histology showed malignant teratoma with undifferentiated malignant epithelium and areas of pronounced differentiation to mucous secreting tubules and smooth muscle (intermediate type $A$ of the T.T.P.R. classification; teratocarcinoma of A.F.I.P. nomenclature) (fig. 6).

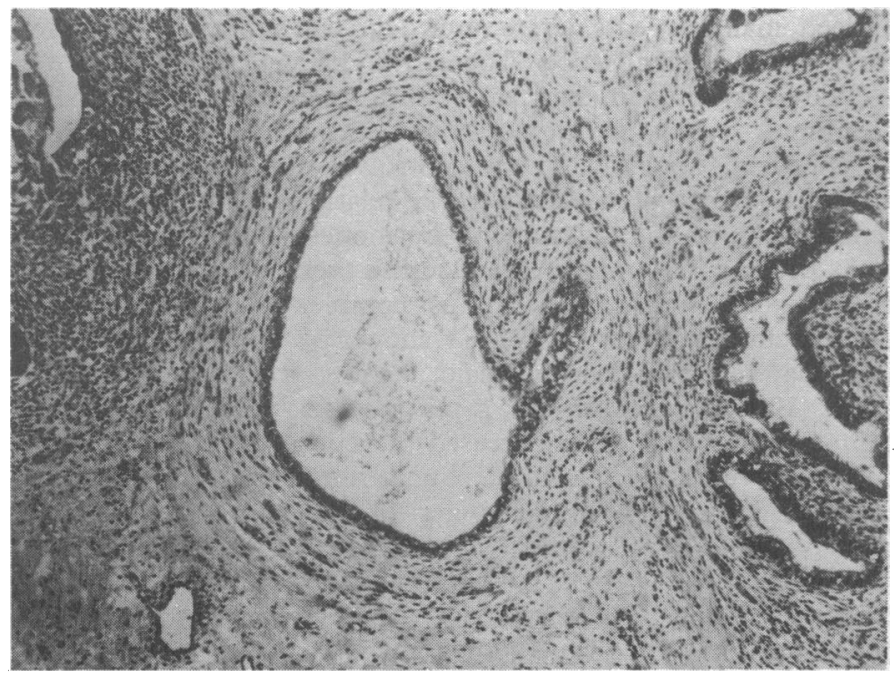

FIG. 6-Case 3. Malignant testicular teratoma (intermediate type A) showing pronounced differentiation to mucous secreting tubules and smooth muscle. $(\times 75$.
Tumour was present in the spermatic cord. A chest $x$-ray picture on 13 January showed multiple small opacities in the lower half of the right lung, confirmed by tomography. Lymphogram showed extensive secondary deposits in the left L3-L4 para-aortic nodes; intravenous pyelogram showed no dye concentration by the left kidney (fig. 7).

Treatment was started on 25 February with a combination of MPA, $100 \mathrm{mg}$ three times daily by mouth, and actinomycin $\mathbf{D}$, $500 \mu \mathrm{g}$ daily, intravenously for five days. The course of actinomycin D

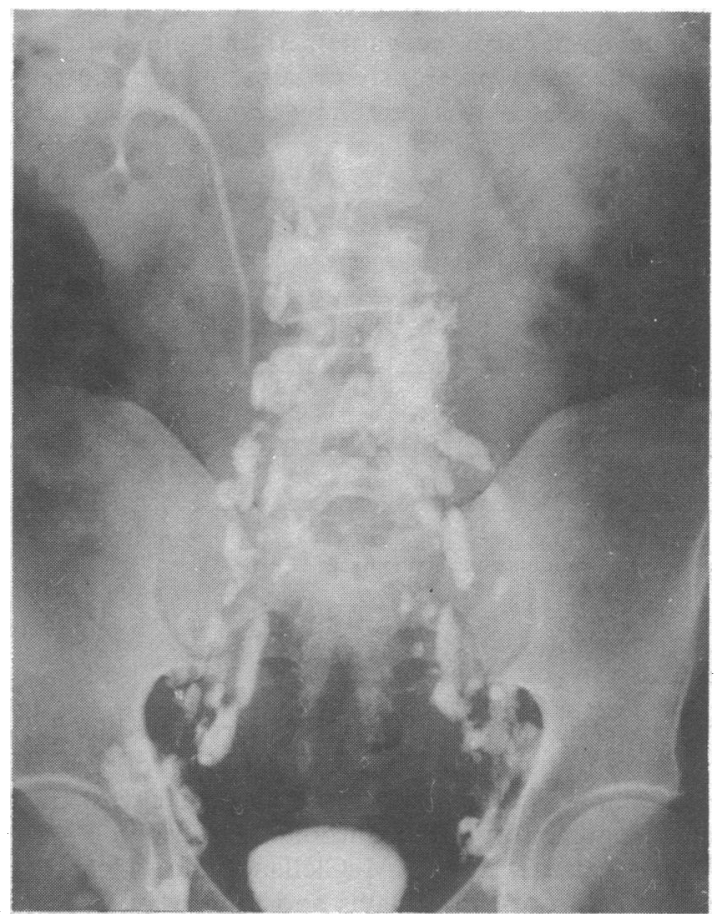

FIG. 7-Case 3. Extensive para-aortic node involvement by testicular teratoma metastases causing ureteric obstruction and non-functioning left kidney.

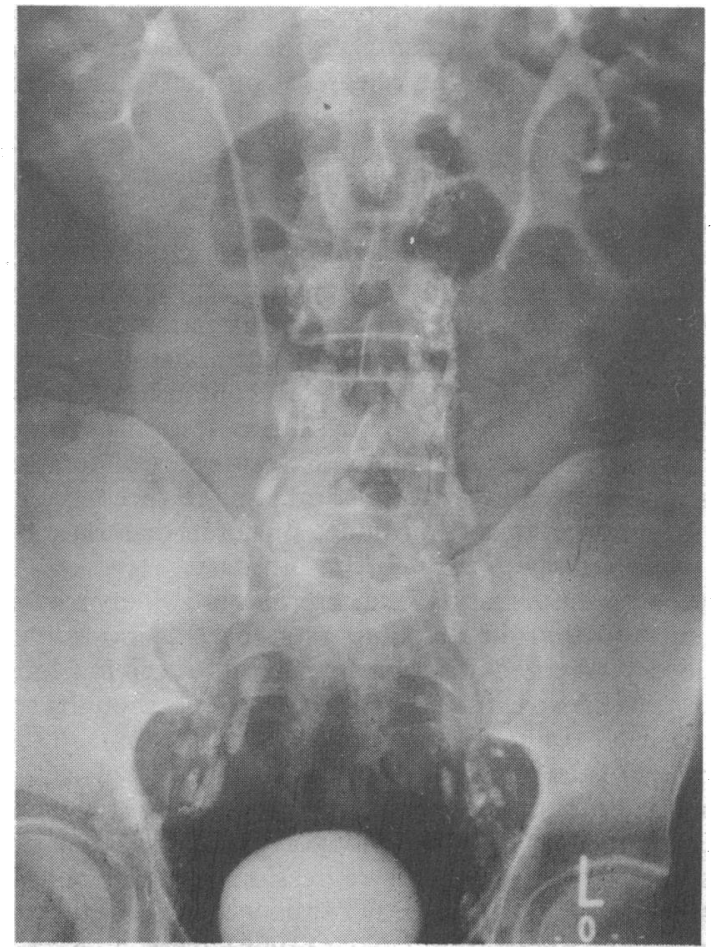

FIG. 8-Case 3. Reduction of para-aortic nodes which remained stationary after receiving combined treatment with actinomycin $D$ and medroxyprogesterone acetate for two years. Note relief of ureteric obstruction and return of normal function to left kidney. 
was repeated every eight weeks for two years, the MPA being given continuously throughout this period. By 12 May 1971 the pulmonary opacities had disappeared; repeat lymphogram showed appreciable reduction in the size of the involved nodes and intravenous pyelogram now showed good excretion by the left kidney. In March 1973 chest $x$-ray pictures, whole lung tomography, and intravenous pyelography showed no tumour recurrence and normal renal function (fig. 8).

This patient is well and clinically tumour-free at two years. We propose to stop actinomycin D but to continue with MPA for a further period of 12 months in gradually decreasing doses.

These three patients showing a good response to treatment are from a series of 16 consecutive cases of advancing metastatic teratoma receiving MPA (see table). All but one of these 16 cases (case 3) failed, either previously or subsequently, to respond to actinomycin D. Case 3 was treated by a combination of MPA and actinomycin $\mathrm{D}$.

Metastatic Testicular Teratomas Response to Medroxyprogesterone

\begin{tabular}{|c|c|c|c|c|c|}
\hline \multicolumn{4}{|c|}{$\begin{array}{c}\text { Teratoma Type } \\
\text { (T.T.P.R.* Classification) }\end{array}$} & \multirow{2}{*}{$\begin{array}{c}\text { Cases } \\
5 \\
8 \\
3\end{array}$} & \multirow{2}{*}{$\begin{array}{c}\begin{array}{c}\text { Marked Objective } \\
\text { Response }\end{array} \\
2 \dagger \\
1 \\
0\end{array}$} \\
\hline $\begin{array}{l}\text { Intermediate A } \\
\text { Intermediate B } \\
\text { Anaplastic } \quad . .\end{array}$ & $\begin{array}{l}\cdots \\
\cdots\end{array}$ & $\because$ & $\begin{array}{l}\cdots \\
\cdots\end{array}$ & & \\
\hline Total & .. & . & .. & 16 & 3 \\
\hline
\end{tabular}

* British Testicular Tumour Panel and Registry.
tOne case also had simultaneous actinomycin D.

\section{Discussion}

Tumour regression in the first two cases reported in the present paper appears to have been induced by high dose oral progesterone therapy. These observations, together with the limited experience reported by other authors (Twombly, 1944; Coutts and Vargas-Zalazar, 1945; McClelland and Richards, 1945; Shivers and Axilrod, 1952; Davis and Shumway, 1958), suggest that by altering the hormonal environment of the host it may be possible to influence the course of some metastatic teratomas towards regression. If this concept is correct, hormone action may be direct and dependent on the presence of specific hormone receptors on the tumour cell, or, alternatively, it may depend on a central action-that is, pituitary gonadotrophin inhibition.

There is some experimental evidence that progesterones, including MPA, inhibit the release of pituitary gonadotrophins causing impairment of spermatogenesis and accessory gland function associated with pronounced degenerative changes in the testis (Ericsson and Dutt, 1965). This may be the cause of the reduction in plasma testosterone levels in normal adult males and sexually precocious boys treated with MPA (Rivarola et al., 1968), and also of the testicular atrophy observed in our rat experiments after prolonged administration of this progesterone (H. J. G. Bloom and J. Dalton, unpublished observations, 1965). On the other hand, Källén and Röhl (1962), who studied the influence of androsterone on human testicular tumours in tissue culture, found that among six examples of teratoma the tumour was arrested in two and stimulated in three. This would favour a direct action of hormones on teratomas rather than a central one meditated through the pituitary.

Based on serial urinary 17-ketosteroid and 17-hydroxysteroid estimation and thyroid function tests there is no evidence of generalized pituitary inhibition in patients receiving long-term high-dose MPA treatment (Bloom, 1972), though selective suppression of follicle stimulating hormone and luteinizing hormone has been reported by Anderson (1972).

With certain tumours that only rarely show a response to treatment with hormones or cytotoxic drugs one must consider the possibility of spontaneous regression being responsible for the observed change. In a study of the world literature between 1900 and 1965 Everson and Cole (1966) were able to collect only nine acceptable examples of spontaneous regression of testicular tumour. Three patients had embryonal carcinoma, three had malignant teratoma, and two choriocarcinoma, while one case was classified as a "round cell carcinoma." Additional examples of spontaneous regression have been reported by Fedon (1960) and by Duari (1967). Occasionally, patients are seen with abdominal node or blood-borne metastases in whom only the remnant or scarring of a previous primary testicular tumour can be found (Friedman, 1951).

The rare event of spontaneous regression is unlikely to be the explanation for the improvement observed in our two cases treated with MPA alone; in both patients the metastases continued to progress, even during treatment with actinomycin $D$, until shortly after MPA was introduced. Were the responses in these two cases possibly due to a delayed effect of actinomycin $D$, appearing only after MPA had been started? In one of Smithers's (1972) patients with pulmonary metastases from an anaplastic teratoma tumour reduction became evident only after the third course of actinomycin $\mathrm{D}$, but this patient was also receiving massive doses of MPA; the excellent response may have been due to this hormone or to the combination of agents, as perhaps in our case 3, and not to the cytotoxic drug alone.

After our preliminary observation in the first two cases reported here, several patients in Smithers's (1972) series also received MPA. Of a total of 18 cases with intermediate $B$ or anaplastic teratoma treated by this author with chemotherapy during 1962 to 1967 tumour regression was observed in six cases, four of which also received MPA. It is interesting that of four patients still living four and a half to seven years at the time of Smithers's report (1972) three had received MPA. The remaining patient was treated with this compound and also testosterone in addition to cytotoxic drugs and died at seven years.

It appears that only teratomas of the intermediate $B$ or anaplastic variety (equivalent to embryonal tumours of the A.F.I.P. nomenclature) may be expected to show a significant response to the cytotoxic agents in current use. The first of our two cases responding to hormone treatment alone had this type of tumour, while the second, and also the patient responding to a combination of actinomycin $\mathrm{D}$ and hormone, are of special interest because their tumours (intermediate $\mathbf{A}$ category) are notoriously resistant to treatment with cytotoxic drugs.

Though there may be a substantial initial response rate of metastatic teratoma to cytotoxic agents, especially with current multiple drug regimens, the fact remains that in any one series chemotherapy has achieved only a small percentage of complete long-term remissions. Furthermore, extensive chemotherapy using single or multiple agents is associated with substantial toxicity: treatment itself can be dangerous and even fatal. The possible value of hormonal agents in the treatment of advanced testicular teratoma is worth exploring further, especially as these compounds are remarkably free from serious side effects. Indeed, many patients derive some degree of subjective improvement even in the absence of objective change.

The rare phenomenon of natural regression in testicular teratomas should provide additional encouragement to explore an endocrine approach to the control of the disease, a similar argument being used elsewhere in relation to the response of renal carcinoma to progestational hormones (Bloom, 1964, 1973).

At present, the choice of endocrine therapy in patients with metastatic testicular teratoma is complex and the response unpredictable. Myers (1959) has shown by nuclear sexing that testicular teratoma may be male, female, or mosaic, and Daly et al. (1963) have described a partially sex-chromatin positive tumour associated with increased secretion of 17-ketosteroids, oestrogen, and pregnanediol. Such tumour characterization, together with endocrine changes in the host, and in-vitro studies using tissue culture in which the direct influence of hormones on the patient's own tumour can be observed, may ultimately help to assess hormone dependency and to select the most appropriate treatment for a particular case.

Testicular teratomas are uncommon tumours, and prospective clinical trials involving a number of centres will be necessary, 
preferably on a national basis, to assess the therapeutic value of hormones, alone or in combination with chemotherapy and irradiation.

We are indebted to Professor N. F. C. Gowing, who is a member of the British Testicular Panel, for reviewing the histological sections and for confirming the type of teratomas according to the panel's classification. Our gratitude is due to Dr. R. G. Jacomb, of Messrs. UpJohn Ltd., for generous supplies of medroxyprogesterone acetate.

\section{References}

Anderson, D. G. (1972). American fournal of Obstetrics and Gynecology, 113, 195.

Bloom, H. J. G. (1964). In Tumours of the Kidney and Ureter, ed. E. W. Riches, p. 311 . London, Livingstone.

Bloom, H. J. G. (1971). British fournal of Cancer, 25, 250.

Bloom, H. J. G. (1972). In Endocrine Therapy in Malignant Disease, ed. B. Stoll, p. 339. London, Saunders.

Bloom, H. J. G. (1973). Cancer (Philadelphia). In press.

Briggs, M. H., Caldwell, A. D. S., and Pitchford, A. G. (1967). Hospital Medicine, 2, 63.

Coutts, W. E., and Vargas-Zalazar, R. (1945). Revista Chilena de Higiene $y$ Medicina Preventiva, 7, 57.
Cox, J. D., Gingerelli, F., Ream, N. W., and Maier, J. G. (1972). Radiology,

Daly, D. W., Dossett, J. A., and Jull, J. W. (1963). British fournal of Surgery,

50, 816.
Davis, P. L., and Shumway, M. H. (1958). Fournal of Urology, 80, 62.

Duari, M. (1967). British Fournal of Clinical Practice, 21, 195.

Ericsson, R. J., and Dutt, R. H. (1965). Endocrinology, 77, 203.

Everson, T. C., and Cole, W. H. (1966). Spontaneous Regression of Cancer. Philadelphia, Saunders.

Fedon, M. (1960). Chirurgia Italiana, 12, 458.

Foley, J. F., Lemon, H. M., Miller, D. M., and Kessinger, A. (1972). Fournal of Urology, 108, 439.

Friedman, N. B. (1951). Cancer (Philadelphia), 4, 265.

Hill, G. J., et al. (1972). Cancer (Philadelphia), 30, 900

Källén, B., and Röhl, L. (1962). Fournal of Urology, 87, 906.

Kennedy, B. J. (1970). Cancer (Philadelphia), 26, 735.

McClelland, J. C., and Richards, G. E. (1945). Transactions of the American Association of Genitourinary Surgeons, 35, 113.

Mackenzie, A. R. (1966). Cancer (Philadelphia), 19, 1369.

Mackenzie, A. R. (1966). Cancer (Philadelphia), 19, 1369.
Myers, L. M. (1959). Fournal of Pathology and Bacteriology, 78, 43. Clinical Endocrinology and Metabolism, 28, 679.

Ronzoni, G., Milano, S., Marin, A. W., and Pagliari, G. (1969). Chirugia e Patologia Sperimentale, 17, 101.

Samuels, M. L., Sullivan, P., and Howe, C. D. (1968). Cancer (Philadelphia), 22, 525.

Shivers, C. H. de T., and Axilrod, H. D. (1952). Fournal of Urology, 67, 537.

Smithers, D. W. (1972). British fournal of Urology, 44, 217.

Twombly, G. H. (1944). Surgery, 16, 181

Werf-Messing, B. Van der. (1973). Clinical Radiology, 24, 121.

\title{
Treatment of Acute Myeloid Leukaemia according to the Hammersmith Protocol: Preliminary Report
}

\author{
W. PAOLINO, L. RESEGOTTI, M. ROSSI, V. INFELISE
}

British Medical fournal, 1973, 3, 567-568

\section{Summary}

A preliminary report is given of a trial of the T.R.A.P. regimen (thioguanine, rubidomycin, cytosine arabinoside, and prednisolone) for the treatment of acute myeloid leukaemia. Out of 27 patients treated $13(48.1 \%)$ obtained complete remission. The treatment was well tolerated and produced especially good results in elderly patients.

\section{Introduction}

Modern therapeutic regimens produce complete remission in most cases of lymphoblastic leukaemia. In contrast the results so far obtained in acute myeloid leukaemia (A.M.L.) are more disappointing, and thus intensive research is needed in this field. We report here the results of a one-year trial of the Hammersmith Hospital protocol as reported by Spiers (1972) for the treatment of patients with A.M.L.

\section{Material and Methods}

Twenty-seven patients were admitted to the trial; 18 were new cases and 9 were already under treatment when the protocol was

\footnotetext{
Departments of Medicine and Haematology, St. John the Baptist Regional Hospital of Turin, Italy

W. PAOLINO, M.D., Consultant Physician and Head of Department

M. ROSSI, M.D., Assistant Physician

V. INFELISE, M.D., Assistant Physician

University of Turin, Italy

L. RESEGOTTI, M.D., Lecturer in Haematology
}

adopted. The latter patients were included either because they had relapsed after a first remission or because a remission could not be obtained with their previous therapy. We have not, however, adopted this protocol for maintenance treatment of patients already in remission induced by other drug combinations. Of the patients studied 16 were women and 11 men. Their distribution according to age is shown in table I.

Treatment was carried out with a modified version of the regimen designated T.R.A.P. by Spiers (1972)-namely, thioguanine $120 \mathrm{mg}$ daily by mouth for five days, rubidomycin (daunorubicin) $40 \mathrm{mg}$ intravenously on day 1 , cytarabine 150 $\mathrm{mg}$ daily intravenously for five days, and prednisolone $50 \mathrm{mg}$ daily by mouth for five days. Each course lasted five days and was administered six times with intervening rest periods of nine days. In two patients with major abnormalities in the E.C.G. at the time of diagnosis we began treatment with C.O.A.P. (Cytoxan (cyclophosphamide), Oncovin (vincristine) A.R.A.C. (cytarabine), and prednisone; Whitecar et al., 1970) and then changed to T.R.A.P. when the E.C.G. showed reversion to normal. After the first six courses (which we regarded as the period of remission induction, even if remission was obtained after three or four courses) treatment was changed to two courses of T.R.A.P. alternating with two courses of C.O.A.P. Supportive measures included blood and platelet transfusions and administration of antibiotics. The treatment was started in hospital and continued in the outpatient department after remission had been achieved.

Remission was regarded as complete when the patient became clinically free of disease and had a normal bone marrow, no anaemia, leucocytes above $2,000 / \mathrm{mm}^{3}$, with more than 1,000 neutrophils, and platelets above $100,000 / \mathrm{mm}^{3}$; and as incomplete when the clinical picture became normal but there were occasional blast cells in the blood or severe neutropenia or thrombocytopenia was present. Failure was inferred when there was no substantial haematological improvement. 